\title{
Nairobi informal settlements: COVID-19 perceptions, prevention practices and impact-Round 3
}

Population Council

Follow this and additional works at: https://knowledgecommons.popcouncil.org/departments_sbsr-pgy

Part of the Demography, Population, and Ecology Commons, and the International Public Health Commons

How does access to this work benefit you? Let us know!

\section{Recommended Citation}

Population Council. 2020. "Nairobi informal settlements: COVID-19 perceptions, prevention practices and impact-Round 3," COVID-19 Research \& Evaluations. Nairobi: Population Council. 


\section{NAIROBI INFORMAL}

SETTLEMENTS: COVID-19

PERCEPTIONS, PREVENTION

PRACTICES \& IMPACT

Population Council Kenya

May 20, 2020 


\section{Overview - Round 3 Data Collection}

- Phone survey conducted on May 10-11

- Kibera, Huruma, Kariobangi, Dandora, Mathare

- 1750 interviews completed ( $87 \%$ of Round 1 )

- 37\% male; $63 \%$ female

- Mean age: 37 years

- 18-24: $21 \%$

- 25-34: $20 \%$

- 35-45: $38 \%$

- >45: $21 \%$

-95\% living in same location as Round 1 


\section{Myths \& Misconceptions on COVID-19}

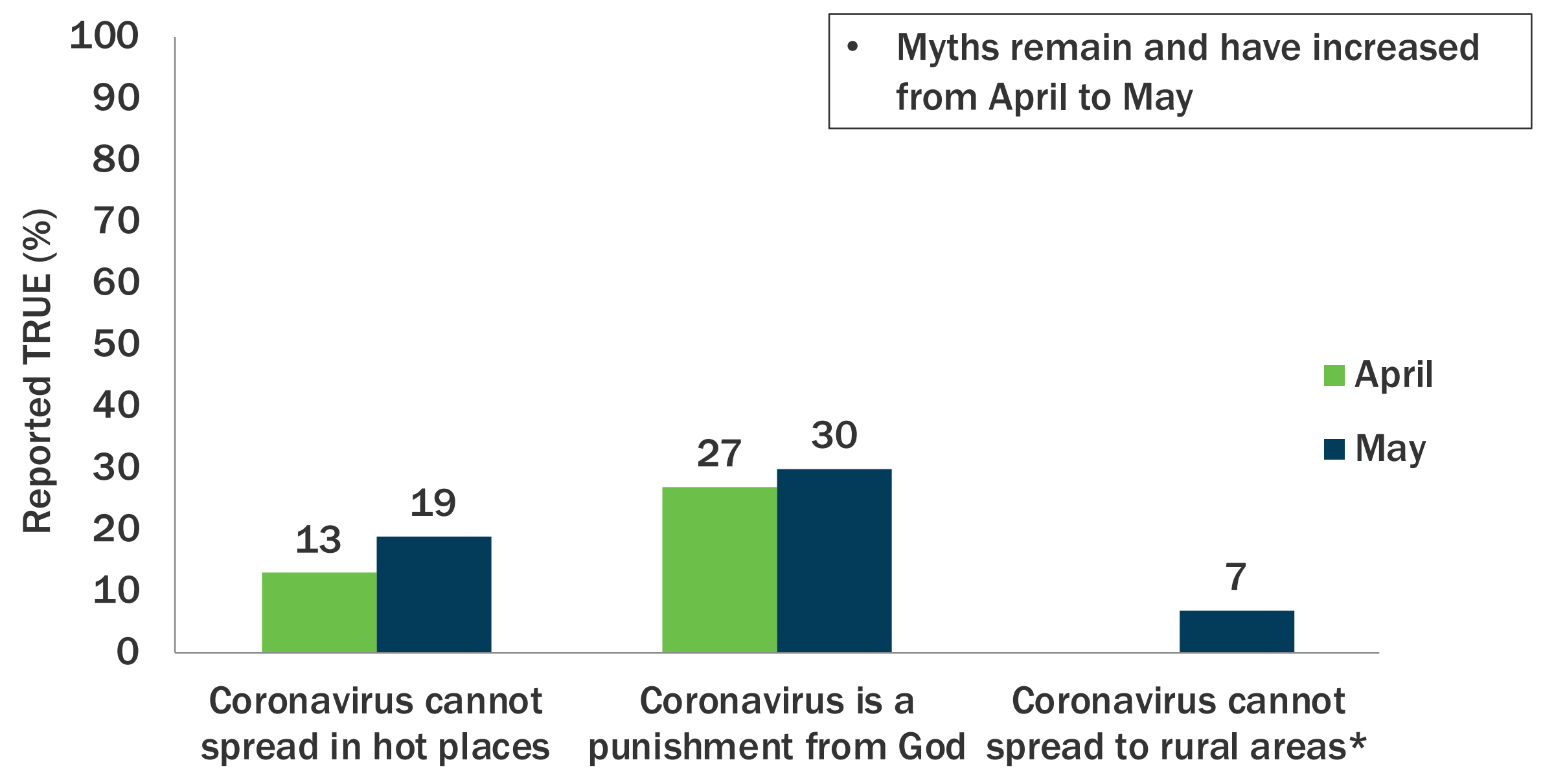

*Question only asked in Round 3 (May) 


\section{What is your risk of being infected?}

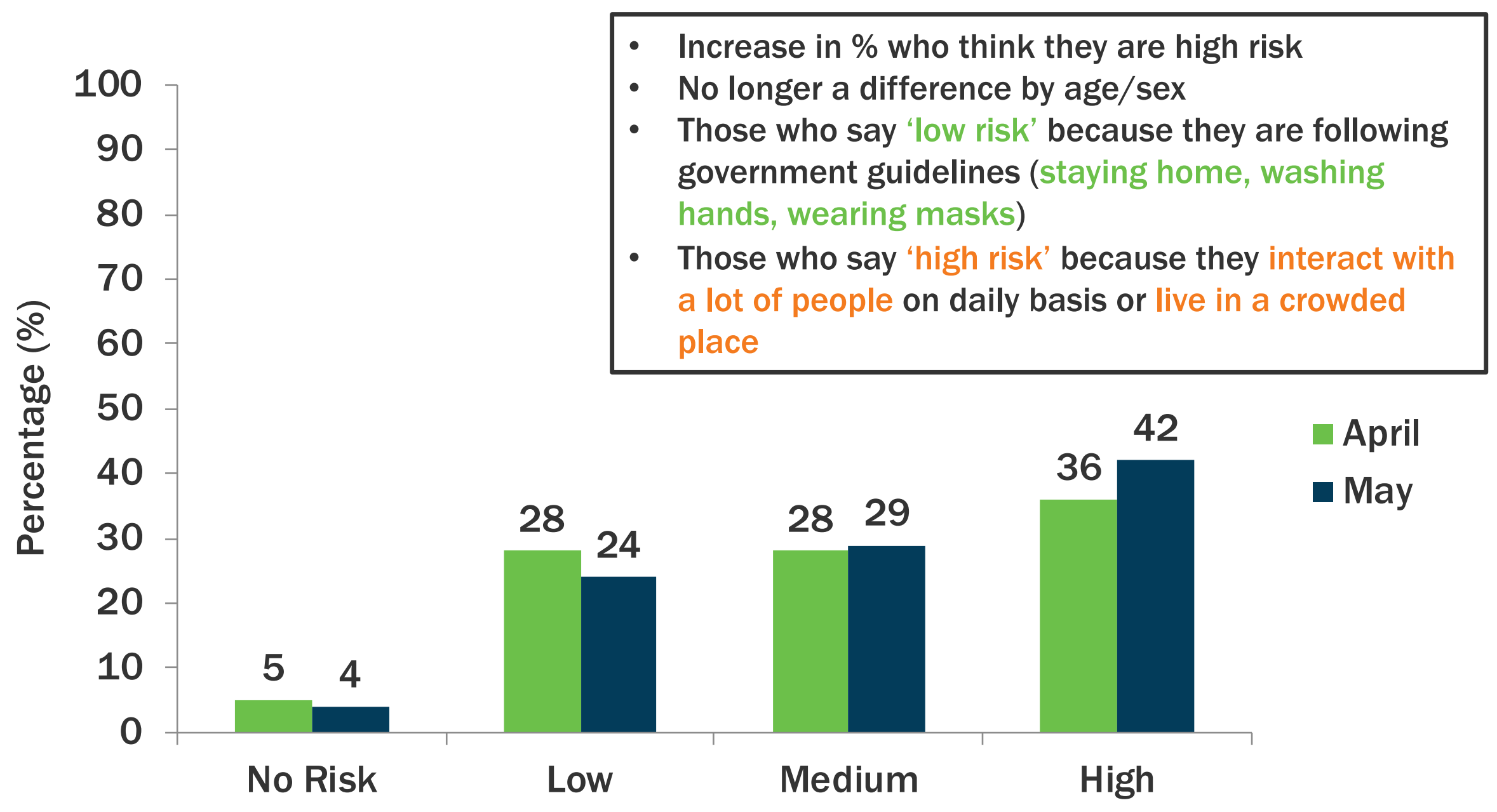




\section{If you had symptoms of COVID-19, what would you do?}

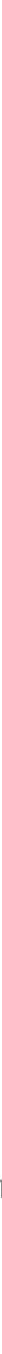

* Not asked in Round 1 


\section{How likely is it you would go for testing if available in your community?}

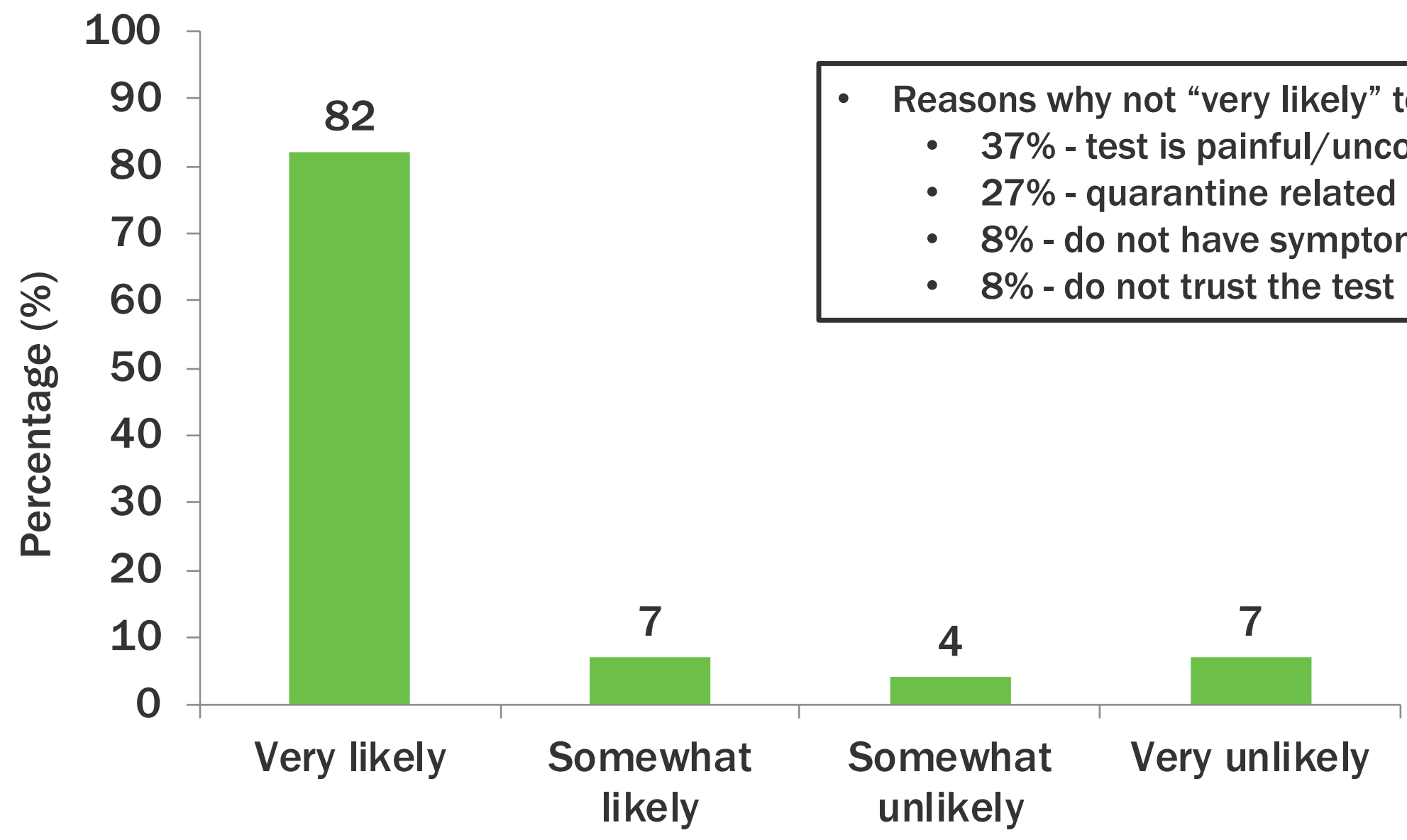




\section{Stigma: "If you tested positive/ were suspected of having COVID-19..."}

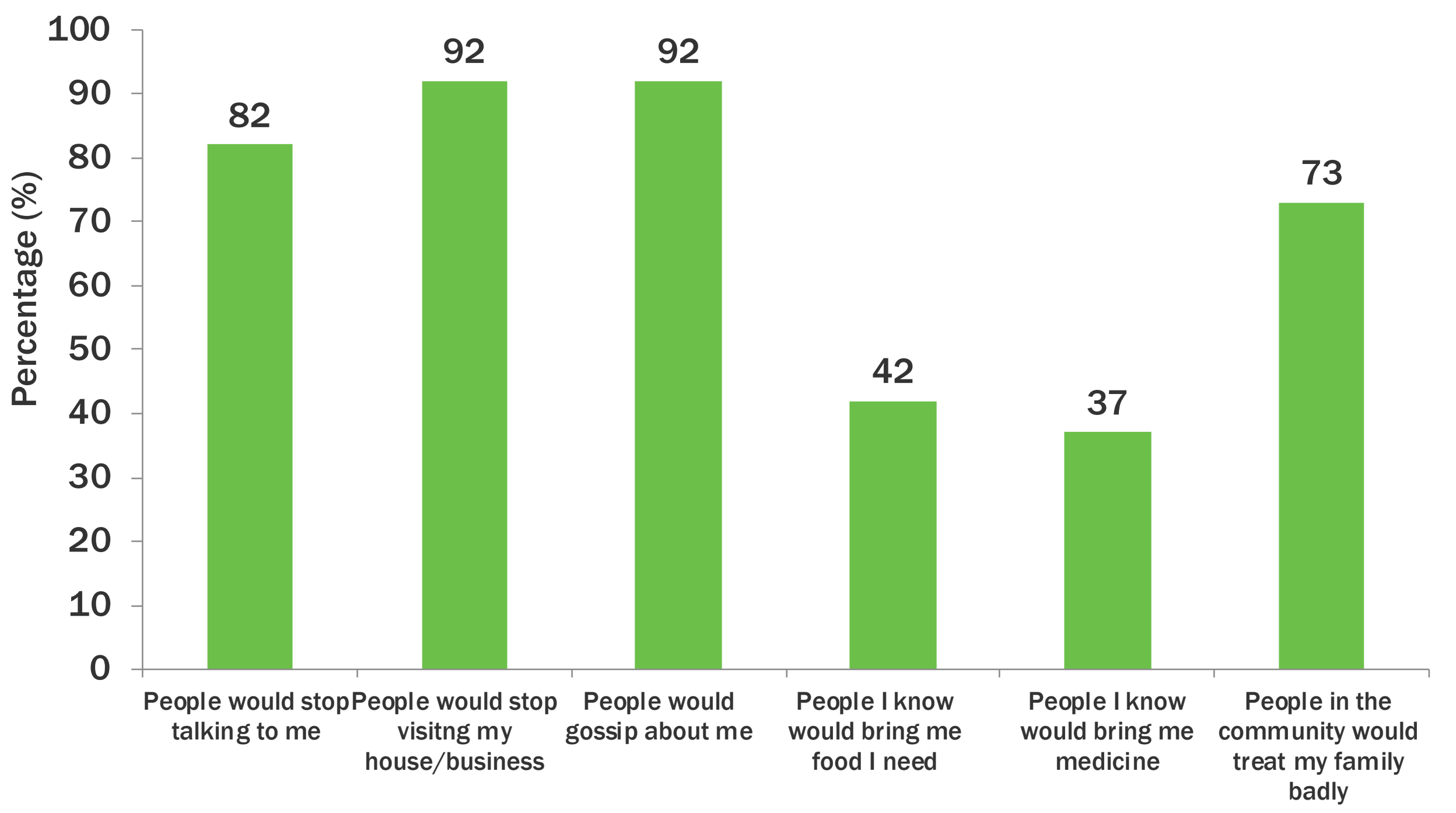




\section{Movement outside home/neighborhood}

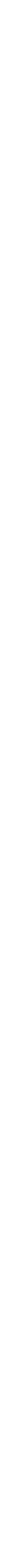




\section{Hand Washing Behavior}

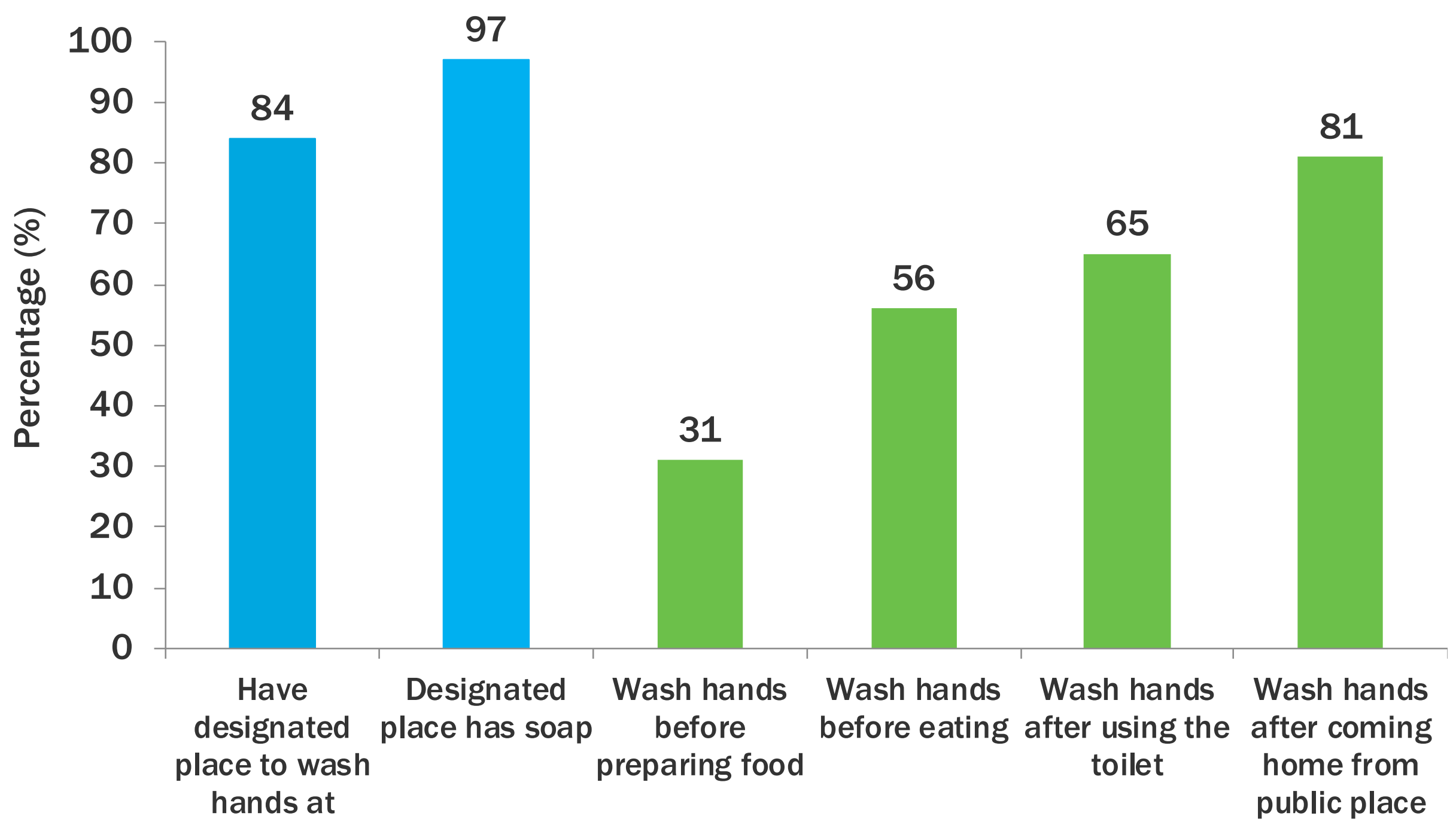

home 


\section{Use of Face Masks is High}

- $88 \%$ report always wearing a mask when outside their house

- 10\% report sometimes wearing a mask

- $83 \%$ use a cloth mask

- 99\% report they do not share; 83\% report washing/changing at least daily

- Over 99\% know mask should cover mouth and nose

- Only 13\% said it should cover chin 


\section{Food Security}

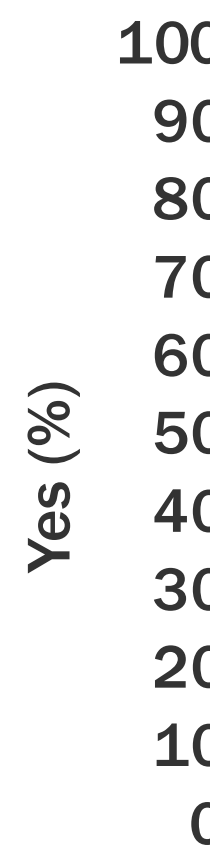

IN MAY:

- $19 \%$ skipping meals every day

- $64 \%$ skipping meals several times per week

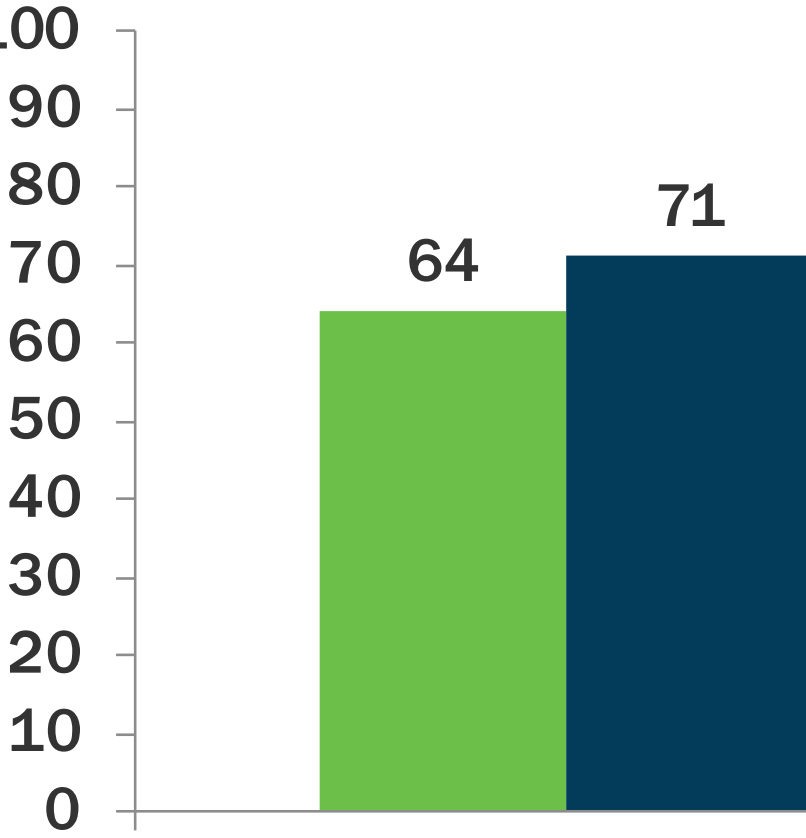

April 2020
77

68

Men

- Women

Skipped Meals/Ate Less in the Past Two Weeks

- 7 out of 10 report that their biggest need currently NOT being addressed is food 


\section{Economic Effects of COVID-19}

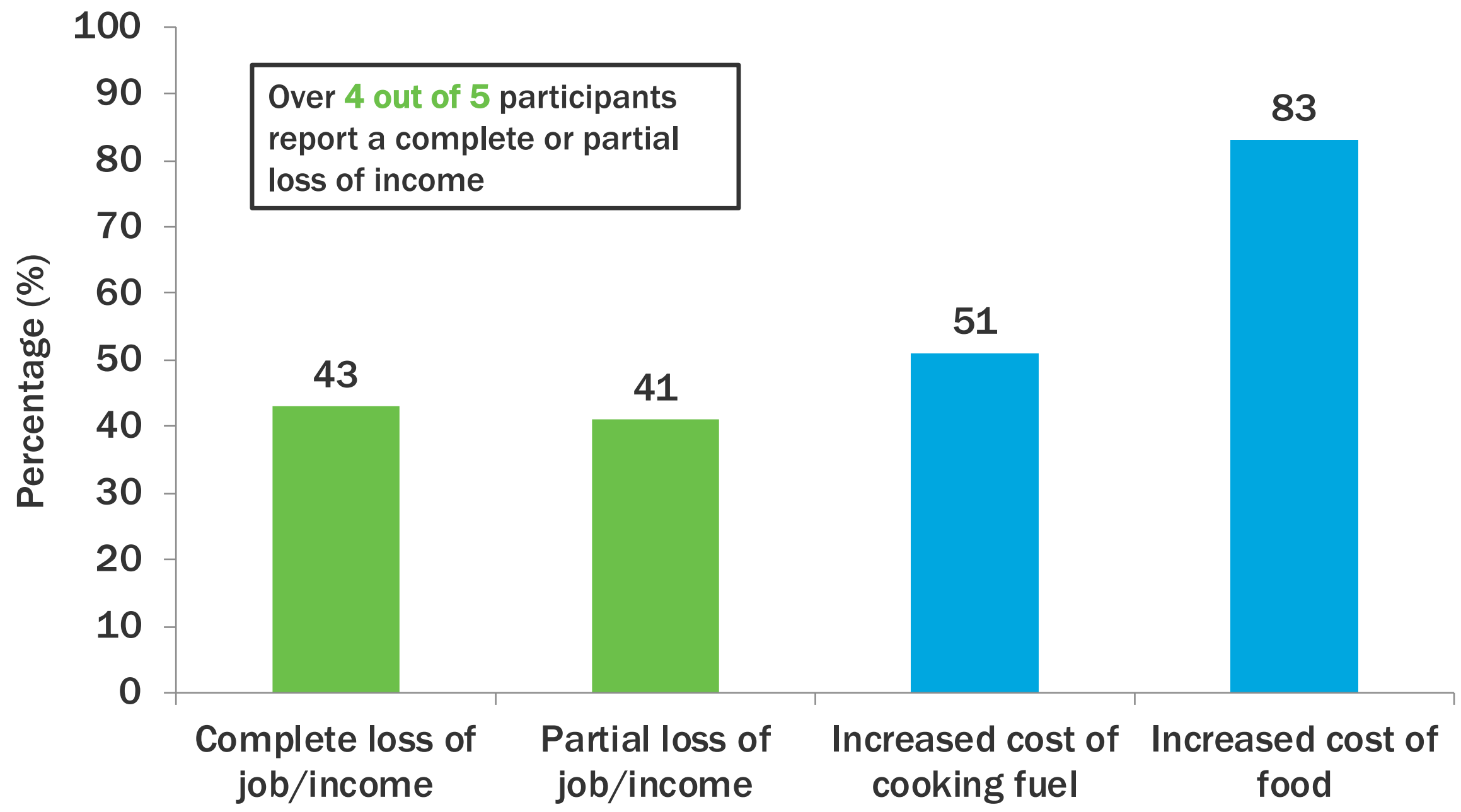




\section{Social Effects of COVID-19}

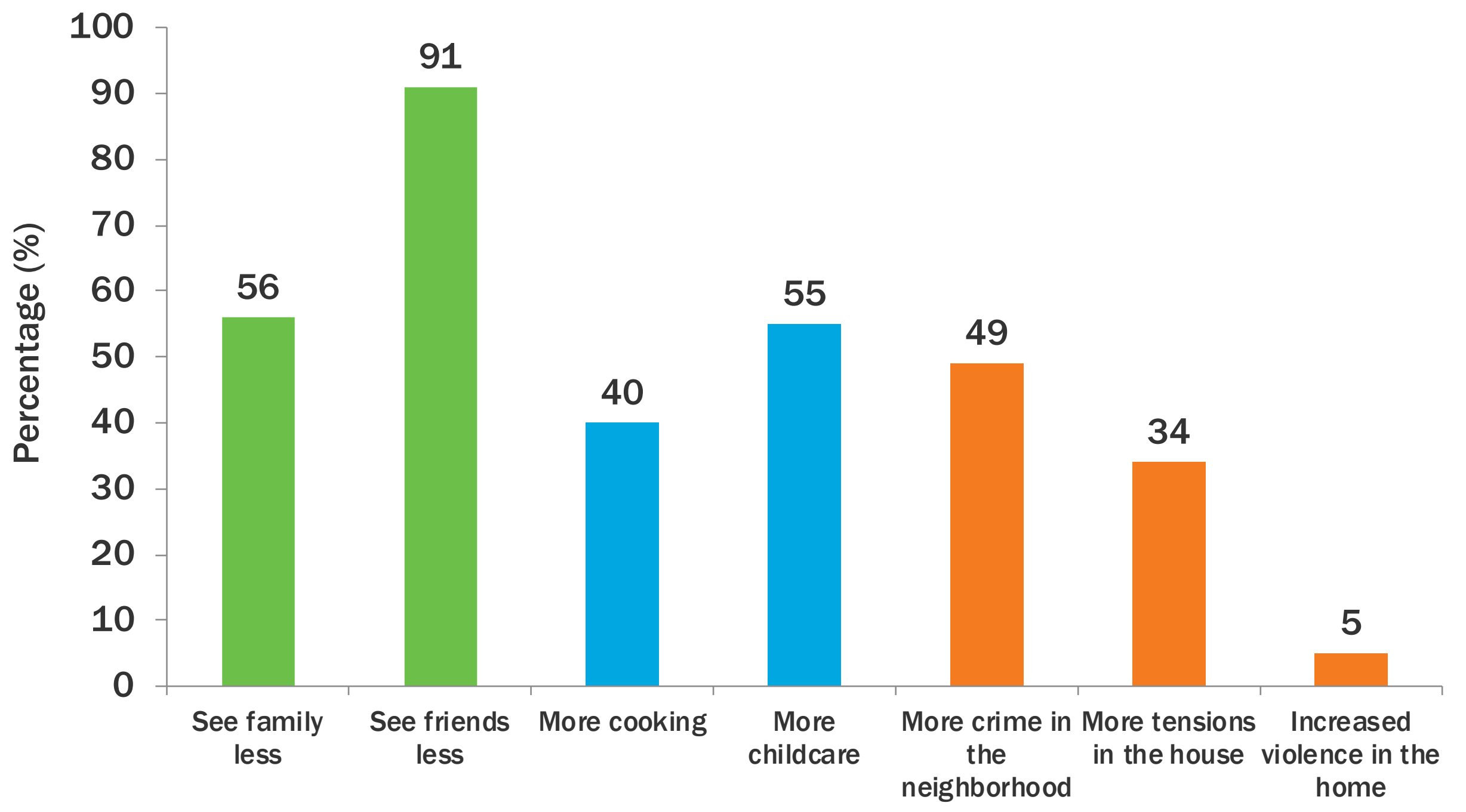




\section{Health Effects of COVID-19}

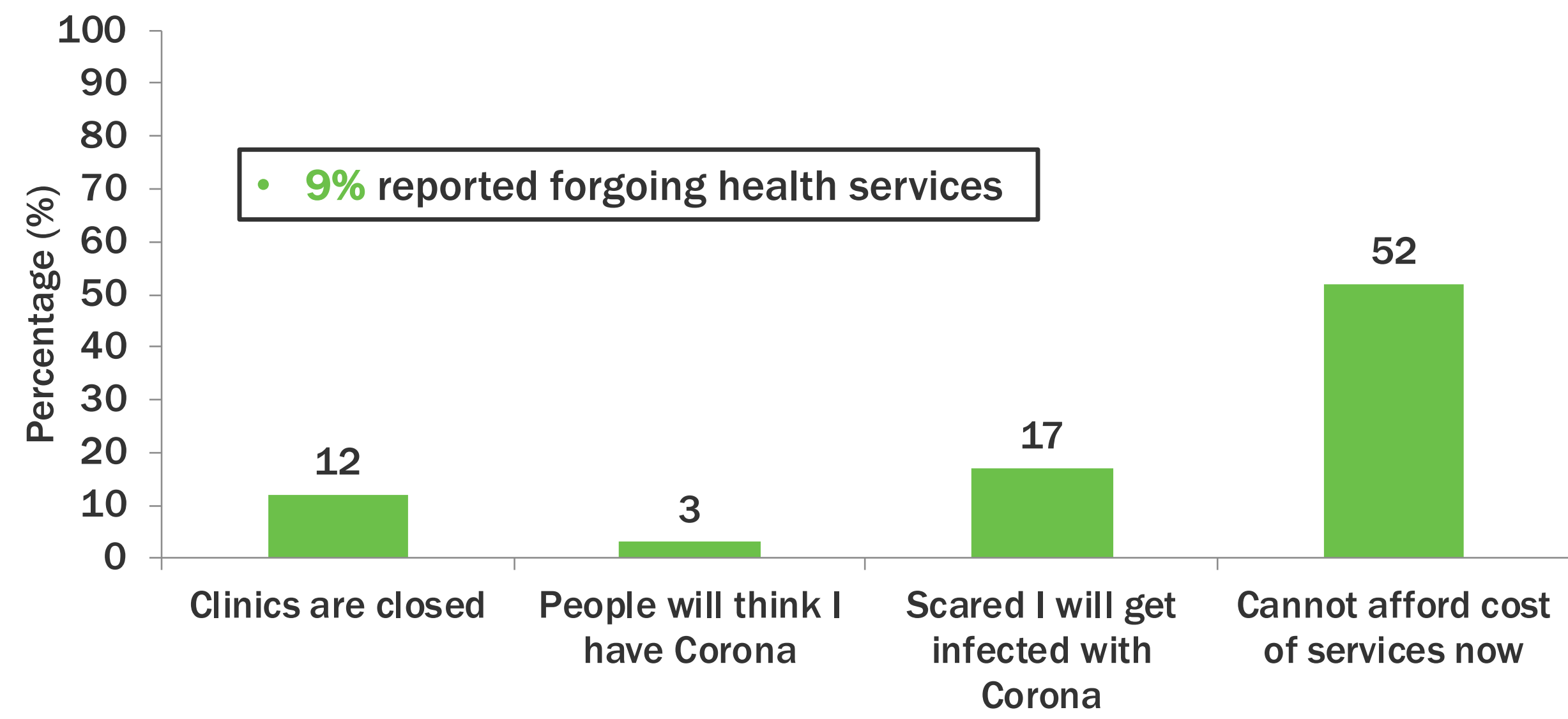

Reason for forgoing health services 


\section{Effects of COVID-19 on children}

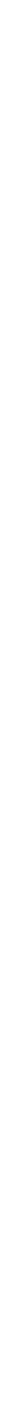




\section{Receiving Assistance?}

- Only $21 \%$ reported receiving assistance (vs $7 \%$ in April)

- Of those that received any assistance:

- 68\% received soap/hand sanitizer

$-30 \%$ food

- Source of assistance:

- 62\% from NGOs

Mismatch between what people say their greatest need is (food) and what they are receiving (soap)

- 35\% from Government

- 17\% from Good Samaritans/corporate donations

Those who received assistance were not those who were most likely to report losing income or missing meals 


\section{Gender Considerations}

- Women are impacted more on many of the social, health and economic dimensions. Compared to men they are more likely to have:

- completely lost their income (47\% v. 36\%)

- increased cleaning (61\% v. 25\%)

- increased childcare (66\% v. 36\%)

- forgone health care services (11\% v. 6\%)

- skipped meals due to COVID-19 (77\% v. 68\%)

- increased violence in the home (6\% v. 3\%) 


\section{Recommendations:}

\section{Public Education Campaigns}

1) Provide clear messaging on what one should do if they have symptoms (self-isolate, call hotline, get tested)

2) Emphasize importance of testing if available in the community; ease worries about pain/quarantine

3) Address stigma $\rightarrow$ people with COVID-19 should be loved and cared for

4) Commend the public for adhering to guidelines on hand washing and face mask wearing 


\section{Recommendations: Social Protection}

1. Address the impacts of income loss and food security, with special attention to women and children

2. Ensure that those most at need of assistance are the ones receiving it

a) Consider ensuring that assistance is getting into the hands of women given their increased burden of social and economic impacts

3. Consider waiving health services fees as cost is the main reason for skipping health care 


\section{Team Members}

- Abuya, Timothy

- Austrian, Karen

- Chebet, Faith

- Isaac, Adan

- Josiah, Margaret

- Kangwana, Beth

- Mbushi, Faith

- Muluve, Eva

- Mwanga, Daniel
- Ngo, Thoai D.

- Nzioki, Mercy

- Ochako, Rhoune

- Ombeva, Joyce

- Orengo, Edwick

- Pinchoff, Jessie

- Tidwell, Ben

- Tse, Christina

- Wanyungu, John

- White, Corinne 
Protocol and questionnaires are openly available, and data available on request.

Please be in touch with the study team if you are interested in collaboration.

\section{For more information contact Karen Austrian (kaustrian@popcouncil.org) or Timothy Abuya (tabuya@popcouncil.org)}

Population Council COVID-19 Research \& Evaluations

Partnering with national health ministries and other government agencies in sub-Saharan Africa, South Asia, and Latin America, Population Council global and in-country scientists are conducting COVID-19 public health and social science research to produce relevant and timely evidence to support policymakers in controlling the spread of coronavirus, evaluating the effectiveness of prevention and mitigation measures, and assessing longer-term health, social and economic effects of the pandemic. 